\title{
Symbiosis initiation in the bacterially luminous sea urchin cardinalfish Siphamia versicolor
}

\author{
P. V. Dunlap*†, A. L. Gould*, M. L. Wittenrich ${ }^{*}$ and M. Nakamura \\ *Department of Ecology and Evolutionary Biology, University of Michigan, Ann Arbor, \\ MI 48109-1048, U.S.A., †Tropical Aquaculture Laboratory, University of Florida, Ruskin, \\ FL 33570, U.S.A. and §Ocean Exposition Commemorative Park Management Foundation, \\ Motobu, Okinawa 905-0206, Japan
}

(Received 4 April 2012, Accepted 22 June 2012)

\begin{abstract}
To determine how each new generation of the sea urchin cardinalfish Siphamia versicolor acquires the symbiotic luminous bacterium Photobacterium mandapamensis, and when in its development the $S$. versicolor initiates the symbiosis, procedures were established for rearing $S$. versicolor larvae in an aposymbiotic state. Under the conditions provided, larvae survived and developed for 28 days after their release from the mouths of males. Notochord flexion began at 8 days post release (dpr). By $28 \mathrm{dpr}$, squamation was evident and the caudal complex was complete. The light organ remained free of bacteria but increased in size and complexity during development of the larvae. Thus, aposymbiotic larvae of the fish can survive and develop for extended periods, major components of the luminescence system develop in the absence of the bacteria and the bacteria are not acquired directly from a parent, via the egg or during mouth brooding. Presentation of the symbiotic bacteria to aposymbiotic larvae at 8-10 dpr, but not earlier, led to initiation of the symbiosis. Upon colonization of the light organ, the bacterial population increased rapidly and cells forming the light-organ chambers exhibited a differentiated appearance. Therefore, the light organ apparently first becomes receptive to colonization after 1 week post-release development, the symbiosis is initiated by bacteria acquired from the environment and bacterial colonization induces morphological changes in the nascent light organ. The abilities to culture larvae of $S$. versicolor for extended periods and to initiate the symbiosis in aposymbiotic larvae are key steps in establishing the experimental tractability of this highly specific vertebrate and microbe mutualism.

(C) 2012 The Authors

Journal of Fish Biology (C 2012 The Fisheries Society of the British Isles
\end{abstract}

Key words: bioluminescence; larval development; mariculture; vertebrate and microbe mutualism.

\section{INTRODUCTION}

The formation of specific pair-wise mutualisms between animals and symbiotic microbes is an important foundation for many marine and terrestrial ecosystems. In forming the symbiosis, the host animal acquires the microbial symbiont's intrinsic metabolism and thereby gains a novel capability important for its survival and expansion into new habitats (Douglas, 1994). For hosts that are obligately dependent on the symbiont for survival, acquisition of the symbiont is a critically important 
life-history event for all members of each new host generation. Symbiont acquisition may be either vertical, acquired directly from a parent, or horizontal, acquired from the environment. How a host animal acquires its specific symbiont, from a parent or from the environment, and when in its development it does so are questions that have been studied intensively in reef-building corals, other cnidarians and many other invertebrate animals (Muller-Parker \& D'Elia, 1997; Weis et al., 2001; Knowlton \& Rohwer, 2003; Nyholm \& McFall-Ngai, 2004; Pasternak et al., 2004). In contrast, little is known about these processes in vertebrate animals that form mutualisms with specific microbes (Dunlap et al., 2007, 2008), despite the diversity and ecological importance of these vertebrates in the marine environment.

Progress has been made recently in understanding the symbiosis of one of these vertebrates, the sea urchin cardinalfish, Siphamia versicolor (Smith \& Radcliffe 1911) (Perciformes: Apogonidae). Siphamia versicolor, a paternal mouth brooder, is found in coral reefs throughout much of the Indo-Pacific region (Breder \& Rosen, 1966; Herring \& Morin, 1978; Nelson, 2006; Froese \& Pauly, 2012). During the day, S. versicolor remains quiescent in small to large groups among the spines of the longspine sea urchin, Diadema setosum (Diadematoida: Diademidae), an association that is inquilinistic (living in close physical association without causing harm; Lachner, 1955; Tamura, 1982) or possibly mutualistic (Eibl-Eibesfeldt, 1961). At dusk, S. versicolor leaves the urchin to forage for zooplankton and begin to emit ventral luminescence, an even blue-green light from chin to caudal peduncle (Masuda \& Allen, 1993; Dunlap \& Nakamura, 2011). The luminescence and feeding behaviour of aquarium-held $S$. versicolor suggest that ventral luminescence in S. versicolor functions to attract and illuminate zooplankton from the reef benthos; ventral luminescence while feeding at dusk might be an adaptive response to predation, allowing $S$. versicolor to forage during the twilight transition quiet period on the reef and avoid both diurnally active and nocturnally active predators (Hobson, 1972, 1991; McFarland et al., 1999; Dunlap \& Nakamura, 2011). Alternatively, ventral luminescence might be used for counter-illumination during migration to, or while feeding at a foraging site. The feeding behaviour of $S$. versicolor and its possible relationship to ventral light emission have not been documented for $S$. versicolor in the wild.

The light emitted by $S$. versicolor is produced by symbiotic, luminous bacteria, a large population of which is cultured within chambers that comprise the core of a ventral light organ located just anterior to the pelvic fins. Light produced by the bacteria is released from the light organ into a ventral diffuser composed of translucent muscle tissue that disperses the light over the ventrum of $S$. versicolor, with the emission of light controlled by a retractable shutter that covers the ventral face of the light organ. Excess bacteria are released from the light organ via a duct into the intestine and from there into the seawater (Iwai, 1958, 1959, 1971; Tominaga, 1964; Haneda, 1965; Yoshiba \& Haneda, 1967; Leis \& Bullock, 1986; Dunlap \& Nakamura, 2011). The bacteria colonizing the light organ of $S$. versicolor, which grow well and luminesce strongly in laboratory culture, have been identified by DNA sequence-based phylogenetic analysis as members of clade II of Photobacterium mandapamensis (Vibrionales: Vibrionaceae) and the genome of a representative strain from symbiosis with S. versicolor has been sequenced (Herring \& Morin, 1978; Leis \& Bullock, 1986; Wada et al., 2006; Kaeding et al., 2007; Urbanczyk et al., $2011 a, b)$. 
The substantial anatomical commitment of $S$. versicolor to culturing its symbiotic bacteria and to ventral emission of the bacterial light, together with the apparent relationship between light emission and feeding (Dunlap \& Nakamura, 2011), indicate that the symbiosis plays a major role in its ecology. Therefore, acquisition of the symbiotic bacteria by each new generation of $S$. versicolor is a critically important event in the life history of this species. Although the developmental inception of light-organ formation in larvae of $S$. versicolor has been documented (Leis \& Bullock, 1986; Dunlap et al., 2009), how and when in its development the fish acquires the symbiotic bacteria remain undefined. Bacteria are not evident in nascent light organs of very small wild-caught larvae or in light organs of larvae cultured for 1 week after their release from the mouth of the brooding male S. versicolor, whereas bacteria are present in the light organs of somewhat larger wild-caught larvae (Leis \& Bullock, 1986; Dunlap et al., 2009). These observations suggest that the bacteria are acquired from the environment and that the symbiosis is initiated soon after the completion of 1 week of post-release larval development. Symbiont acquisition in S. versicolor, however, has not been documented, and parental transfer of the bacteria to the new generation, maternally via the egg or paternally during mouth brooding, remains a possibility. In this study, to address and resolve these issues, procedures were established for rearing of $S$. versicolor larvae in a symbiont-free state and for reconstituting the symbiosis.

\section{MATERIALS AND METHODS}

\section{CAPTURE, CARE AND HANDLING OF S. VERSICOLOR}

Groups of adult and juvenile specimens of $S$. versicolor were captured by scuba diving, together with individual urchins, D. setosum, from coral reefs at 3-6 m depth at Sesoko Island, northern Okinawa, Japan $\left(26^{\circ} 64^{\prime} \mathrm{N} ; 127^{\circ} 87^{\prime} \mathrm{E}\right)$. The captured $S$. versicolor were maintained with the sea urchins in 601 rectangular glass aquaria with flowing natural seawater and aeration under ambient natural light and temperature conditions $\left(26^{\circ} 64^{\prime} \mathrm{N}\right)$. Aquarium seawater temperature and salinity ranged from 25 to $29^{\circ} \mathrm{C}$ and 34 to 35, respectively. Siphamia versicolor were fed daily on small crustaceans and other zooplankton captured by night-lighting (Kimura et al., 1984) at Sesoko Station dock using a $30 \mathrm{~cm}$ diameter, $1.05 \mathrm{~m}$ length, $53 \mu \mathrm{m}$ mesh net. Survival of adult and juvenile S. versicolor was $>95 \%$ for over 2 months under the conditions provided. This species is not protected and is not on the International Union for Conservation (IUCN) of Nature Red List of Threatened Species. The methods used in this study for the capture, care and handling of $S$. versicolor conform with the University of the Ryukyus Guide for Care and Use of Laboratory Animals (Dobutsu Jikken Kisoku, version 19.6.26), and the protocols used here were approved by the University of Michigan University Committee on Use and Care of Animals.

\section{IDENTIFICATION}

The fish examined in this study were identified as $S$. versicolor based on information from Tominaga (1964) as well as information from Froese \& Pauly (2012), Haneda (1965) and Iwai (1971). The taxonomy of Siphamia, however, is under revision (O. Gon, G. Gouws, G. R. Allen \& P. Dunlap, unpubl. data) and the species epithet used here might change. Therefore, for future taxonomic reference, specimens of this fish have been deposited in the Fish Collection of the University of Michigan Museum of Zoology under catalogue number UMMZ 248762 and the Marine Vertebrate Collection of the Scripps Institution of Oceanography under catalogue number SIO 10-98 (Dunlap \& Nakamura, 2011). 


\section{MARICULTURE AND EXPERIMENTAL COLONIZATION OF LARVAE}

Brooding males, recognized by the distended lower jaw and branchiostegal membrane, were monitored daily for the release of larvae. While being brooded, embryos develop and hatch as post-embryos (yolk remaining), develop further into pre-release larvae (yolk completely absorbed) and then are released from the male's mouth as full-term pre-flexion larvae (yolk absent) (Dunlap et al., 2009). Hatching is not easily observed without disrupting brooding and the time between hatching and release from the male's mouth is not known with certainty. Therefore, the timing of larval development is reported here as days after their release from the male, i.e. days post release (dpr) instead of days post-hatch. Larvae $0 \mathrm{dpr}$ were transferred in bulk seawater to 2001 round tanks containing natural seawater that was gently circulated, aerated and maintained at $25-27^{\circ} \mathrm{C}$ (Wittenrich, 2007). The seawater delivered to the rearing tanks, pumped from $c .100 \mathrm{~m}$ offshore, contained very low to undetectable numbers of luminous bacteria. The larval rearing tanks were illuminated continuously (24L:0D) with two $40 \mathrm{~W}$ fluorescent bulbs mounted $c .25 \mathrm{~cm}$ above the water surface; continuous lighting has been shown to promote better larval feeding success and survival (Arvedlund et al., 2000; Puvanendran \& Brown, 2002). Larvae were pulse-fed mixtures of rotifers Brachionus plicatilis fed live Chlorella (Nama Chlorella V-12, Kyowa Hakko Kogyo; www.kyowa.co.jp) and size-sorted wild-caught zooplankton. Initial zooplankton feed was the 53-243 $\mu \mathrm{m}$ fraction, with increasing prey sizes (i.e. 300 and $500 \mu \mathrm{m}$ upper size cut-offs) as the larvae grew. To enhance visual acuity of the larvae and thereby improve feeding performance, the water of the larval rearing tanks was made green by the addition of Nannochloropsis (Nanno 3600, Reed Mariculture; http://reed-mariculture.com), c. $4 \mathrm{ml}$ per 2001 (Wittenrich, 2007). Under these conditions, survival of larvae in most batches was at least $10-30 \%$ beyond 7 days, and in many batches survival ranged from $c$. 20-70\% for 10-14 days. Survival rates could not be determined with precision, however, due to the nature of the mariculture system (large tank volume, freely swimming larvae and restricted visibility due to algae).

To initiate bacterial colonization of the light organs of aposymbiotic larvae, natively symbiotic bacteria present in the freshly voided faeces of adults (Dunlap \& Nakamura, 2011) and individual strains of the bacteria isolated from light organs of adult S. versicolor and grown in laboratory culture (on LSW-70 medium) were mixed with live zooplankton in seawater at an initial concentration of $c .10^{5}-10^{6}$ cells $\mathrm{ml}^{-1}$; the mix was aerated for $10-12 \mathrm{~h}$ and then partially filtered through $53 \mu \mathrm{m}$ mesh screen to concentrate the zooplankton before addition of the zooplankton in seawater to larval mariculture tanks. Whether the bacteria are ingested from the seawater or from association with the zooplankton is not yet known. Furthermore, the minimum number of symbiotic bacteria necessary to effect colonization of the larval light organ is not yet known. Between colonization experiments, the rearing tanks were emptied and cleaned.

\section{MICROBIOLOGICAL ANALYSIS}

To determine if bacteria were present in light organs, individual larvae were taken from the rearing tanks and placed in filter-sterilized $(0.2 \mu \mathrm{m}$ pore size $)$ natural seawater to which sufficient tricaine methanesulphonate (MS-222, Sigma-Aldrich; www.sigmaaldrich.com) was added, $c .75-100 \mathrm{mg} \mathrm{l}^{-1}$, to cause cessation of swimming and respiratory movement within $10 \mathrm{~s}$; the light organ was then aseptically dissected from $S$. versicolor under magnification using a dissecting microscope. The light organ was rinsed in buffered [25 mM 4-(2hydroxyethyl)-1-piperazine-ethane-sulphonic acid (HEPES), pH 7.25] 70\% seawater (BSW70 , filter sterilized), gently blotted on filter paper and homogenized in $0.5 \mathrm{ml}$ of BSW-70 in a sterile, hand-held $1 \mathrm{ml}$ tissue grinder. The entire homogenate or a portion of it was then spread onto plates of LSW-70 agar medium (Kaeding et al., 2007), which contained $10 \mathrm{~g} \mathrm{l}^{-1}$ of tryptone, $5 \mathrm{~g}^{-1}$ yeast extract, $700 \mathrm{ml} \mathrm{l}^{-1}$ seawater, $300 \mathrm{ml} \mathrm{l}^{-1}$ de-ionized water and $15 \mathrm{~g} \mathrm{l}^{-1}$ of agar. The inoculated plates were incubated at room temperature $\left(27-29^{\circ} \mathrm{C}\right)$ for $12-18 \mathrm{~h}$ and then examined in the light and in the dark in a photographic darkroom to determine if bacterial colonies were present and luminous. Digital images of the plates containing colonies were captured in the light and in the dark using a Nikon D200 SLR camera (www.nikon.com) at 400 ASA on bulb setting (typically, $1 \mathrm{~s}$ exposure in the light and 
2-4 min exposure in the dark). Representative strains of luminous bacteria from these plates were purified on LSW-70 agar medium and retained. Retained strains were grown overnight with aeration in LSW-70 broth and DNA was extracted and purified from $1 \mathrm{ml}$ volumes of the overnight cultures. For bacterial species identification, the luxA gene was PCR amplified, sequenced and analysed using previously described procedures (Kaeding et al., 2007). Sequence of the luxA gene provides a rapid and accurate species and clade identification of luminous bacteria (Ast \& Dunlap, 2004; Kaeding et al., 2007; Ast et al., 2009).

\section{MORPHOLOGICAL ANALYSIS}

Larval body length (notochord length, $L_{\mathrm{N}}$, before notochord flexion, and standard length, $L_{S}$, at and after the onset of flexion) was measured as soon as possible after $S$. versicolor were sampled and before exposure to MS-222. Upon cessation of respiration in response to the addition of MS-222, larvae were seen to shrink somewhat, possibly due to fluid loss upon cessation of osmoregulation. Digital images of specimens were captured with a Canon PowerShot G11 camera (www.canon.com) through the lens of a standard dissecting microscope.

For histological analysis of light organs, individual larvae were anaesthetized with MS222 and fixed in standard Bouin's solution (EM Sciences; http://emsdiasum.com). Embedding, sectioning $(4 \mu \mathrm{m})$ and staining with haematoxylin and eosin followed standard histological protocols. For examination of thin sections, individual anaesthetized larvae were preserved in Karnovsky's solution (2\% paraformaldehyde, $2.5 \%$ glutaraldehyde and $0.1 \mathrm{M}$ sodium phosphate buffer; EM Sciences) and stored at $4^{\circ} \mathrm{C}$ until processed. Intact larvae or portions containing the light organ were then washed in phosphate buffer, post-fixed in buffered osmium tetroxide (1\%) for $1 \mathrm{~h}$ and then rinsed, dehydrated in ascending strengths of ethanol, infiltrated with propylene oxide, infiltrated with polyembed 812 epoxy resin and polymerized. Thin sections $(0.5$ or $0.7 \mu \mathrm{M})$ were stained with toluidine blue. Histological and thin sections were examined and digital images were captured with an Olympus BX53 microscope mounted with an Olympus DP72 camera (www.olympus.com).

\section{RESULTS}

\section{APOSYMBIOTIC MARICULTURE OF S. VERSICOLOR LARVAE}

To determine if $S$. versicolor can survive in an aposymbiotic state, post-release larvae were cultured using mariculture conditions that included large tank volume, continuous illumination, addition of unicellular algae and high concentrations of sizesorted zooplankton prey. Under these conditions, survival was substantially enhanced over earlier results (Dunlap et al., 2009); large numbers of larvae released from several individual male $S$. versicolor survived well beyond $7 \mathrm{dpr}$, with some larvae surviving for $28 \mathrm{dpr}$, the longest mariculture trial attempted.

The larvae exhibited substantial growth and development over the 28 days of culture (Fig. 1). Beginning at c. $2.2 \mathrm{~mm} L_{\mathrm{N}}$ at $1 \mathrm{dpr}$, larvae attained $6.2 \mathrm{~mm} L_{\mathrm{S}}$ at 28 dpr. The supraoccipital spine noted by Leis \& Bullock (1986) in wild-caught S. versicolor larvae at $2.2 \mathrm{~mm} L_{\mathrm{N}}$ begins to form at $2 \mathrm{dpr}$, becomes prominent by $7 \mathrm{dpr}$ and thereafter gradually decreases relative to increasing head size. Notochord flexion began between 7 and $8 \mathrm{dpr}$. Fin rays became evident by $7 \mathrm{dpr}$ in pre-flexion larvae and became distinct generally within an additional day of development, in concert with the onset of notochord flexion. The spines of the first dorsal fin were distinct in larvae at $16 \mathrm{dpr}$, at a size, $5.6 \mathrm{~mm} L_{S}$, very similar to the size noted for this trait by Leis \& Bullock (1986) for wild-caught larvae. Along with a deepening of the body, head and body pigmentation increased during early stages of development, essentially as described by Leis \& Bullock (1986). The ventral diffuser, 

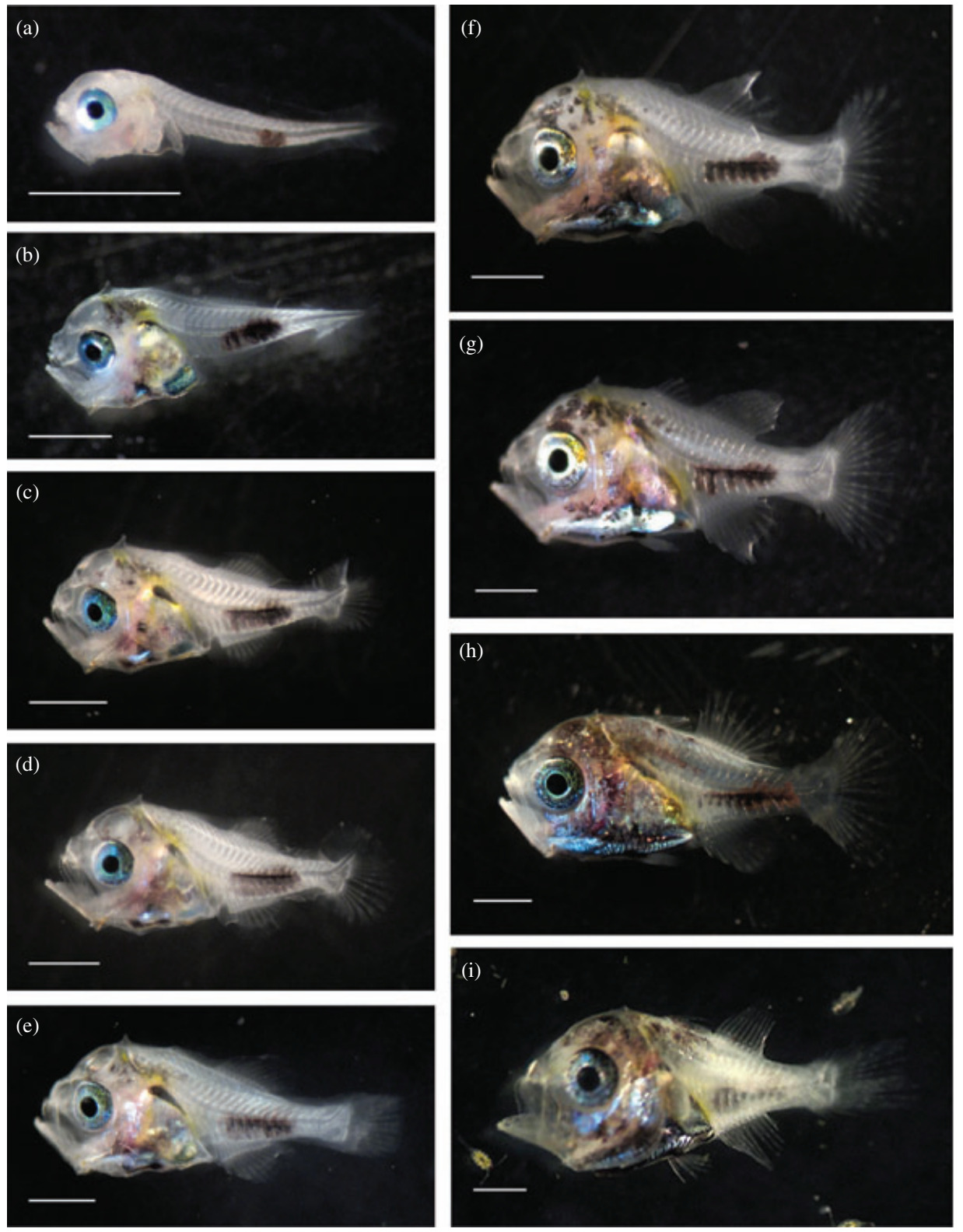

FIG. 1. Aposymbiotically cultured larvae of Siphamia versicolor at the conclusion of days post-release (dpr) development: (a) $1 \mathrm{dpr}, 2.2 \mathrm{~mm}$ notochord length, $L_{\mathrm{N}}$, (b) $7 \mathrm{dpr}, 3.9 \mathrm{~mm} L_{\mathrm{N}}$, (c) $8 \mathrm{dpr}, 3.9 \mathrm{~mm}$ standard length, $L_{\mathrm{S}}$, (d) $10 \mathrm{dpr}, 4.1 \mathrm{~mm} L_{\mathrm{S}}$, (e) $11.5 \mathrm{dpr}, 4.7 \mathrm{~mm} L_{\mathrm{S}}$, (f) $14 \mathrm{dpr}, 5.0 \mathrm{~mm} L_{\mathrm{S}}$, (g) $16 \mathrm{dpr}, 5.6 \mathrm{~mm}$ $L_{\mathrm{S}}$, (h) $18 \mathrm{dpr}, 5.7 \mathrm{~mm} L_{\mathrm{S}}$ and (i) $28 \mathrm{dpr}, 6.2 \mathrm{~mm} L_{\mathrm{S}}$. All scale bars $=1.0 \mathrm{~mm}$.

first evident as a localized cluster of melanophores associated with the nascent light organ in larvae at $7 \mathrm{dpr}$, developed a silvery appearance and progressively enlarged, becoming more silvery and reaching anteriorly to the gular area and posteriorly to the anal fin by $18 \mathrm{dpr}$. The silver and black striations characteristic of the ventral 


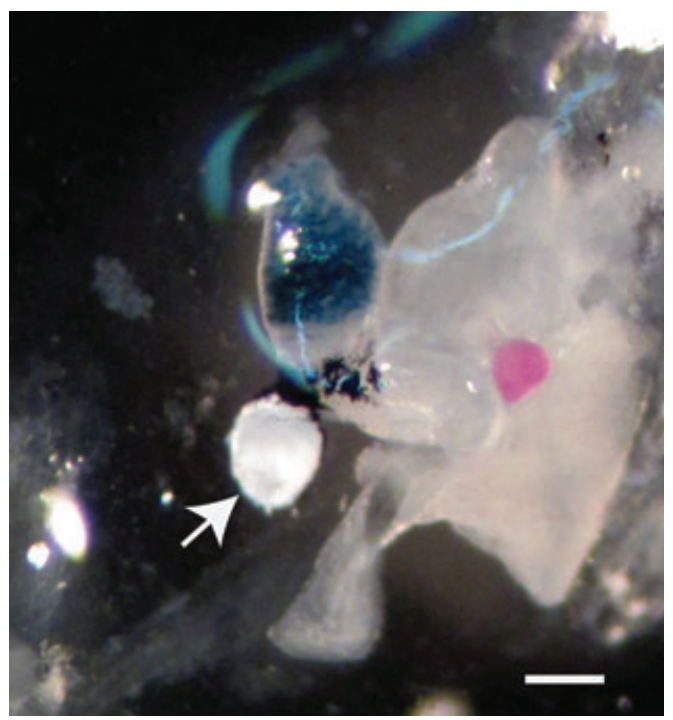

FIG. 2. Light organ of aposymbiotically cultured Siphamia versicolor larva. The light organ $(\rightarrow)$ was dissected from the larval specimen shown in Fig. 1(f), which had been cultured through 14 days of post-release development. Immediately after the photograph was taken, the light organ was aseptically removed from associated tissues of the gut and then homogenized. No bacterial colonies arose from plating of the light-organ homogenate on a nutrient seawater-based medium that supports the growth of the symbiotic (and other) bacteria. Scale bar $=0.2 \mathrm{~mm}$.

diffuser in juvenile and adult $S$. versicolor began to appear by $14 \mathrm{dpr}$, and they became progressively more distinct with further development [Fig. 1(h)]. By 28 dpr, squamation was evident and the caudal complex appeared to be complete [Fig. 1(i)].

To determine if the larvae remained aposymbiotic under these mariculture conditions, their light organs were examined for the presence of the symbiotic bacteria. Larvae were sampled at 10, 11.5, 14, 16 and 28 dpr. In all cases, the light organs, which had continued to develop as the fish grew (Fig. 2), were found to be devoid of bacteria; no bacterial colonies arose from platings of light organs aseptically removed from the larvae and no bacteria were seen in thin sections of the light organs (Fig. 3). These results establish that larvae of $S$. versicolor, following their release from the male's mouth, survive well and can be cultured in an aposymbiotic state through at least $28 \mathrm{dpr}$ development. Furthermore, the absence of the symbiotic bacteria in the light organs of late-stage larvae, at 18 and $28 \mathrm{dpr}$, indicates that the bacteria are not transferred parentally to the new generation of $S$. versicolor, either maternally via the egg or paternally during mouth brooding.

\section{EXPERIMENTAL COLONIZATION}

The ability to culture larvae of $S$. versicolor in an aposymbiotic state allowed experimental initiation of the symbiosis to be tested. Previous observations suggested that in the wild the light organ of $S$. versicolor becomes colonized by bacteria at some point after 7 dpr (Leis \& Bullock, 1986; Dunlap et al., 2009). Larvae were cultured aposymbiotically to $10 \mathrm{dpr}$ and examined for their ability to initiate the symbiosis. 

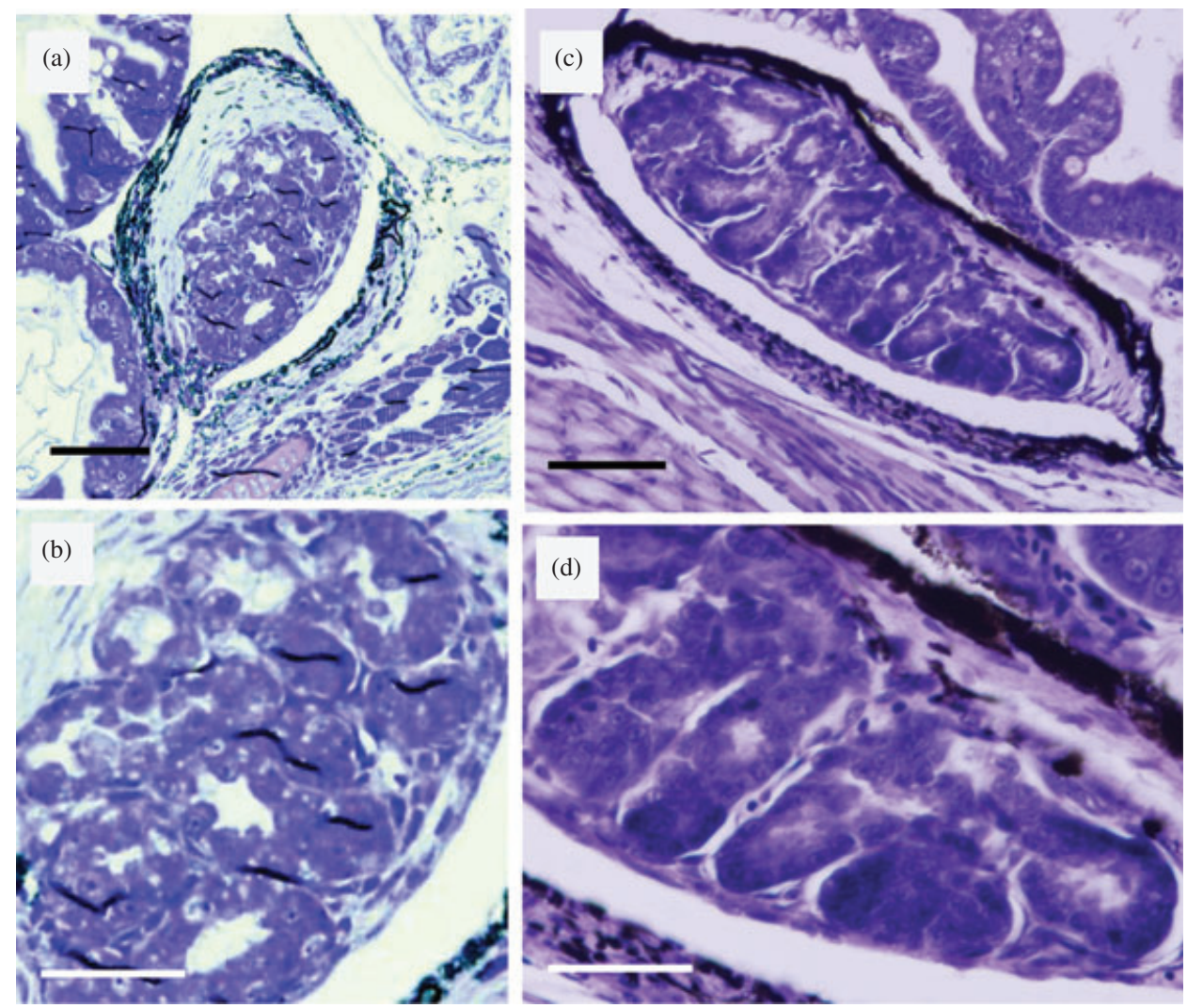

FIG. 3. Light organs of aposymbiotically cultured Siphamia versicolor larva. (a) Thin section $(0.5 \mu \mathrm{m})$ of the light organ of a larval specimen cultured through 11.5 days of post-release (dpr) development. Ventral is to the lower right corner. Scale bar $=50 \mu \mathrm{m}$. (b) Close up of (a) (scale bar $=25 \mu \mathrm{m}$ ) to show the swollen undifferentiated cells forming the light-organ chambers and the absence of bacteria in the chamber lumina. (c) Thin section $(0.7 \mu \mathrm{m})$ of the light organ of a larval specimen cultured through $16 \mathrm{dpr}$ development. Ventral is to the lower left corner. Scale bar $=70 \mu \mathrm{m}$. (d) Close up of (c) (scale bar $=30 \mu \mathrm{m}$ ) to show the swollen undifferentiated cells forming the light-organ chambers and the absence of bacteria in the chamber lumina. The developing multilayered reflector dorsal to the light organ and the tissues ventral to the light organ that presumably will form the shutter (Dunlap \& Nakamura, 2011) can be seen in (a) and (c). Sections were stained with toluidine blue.

The symbiotic bacteria were presented to larvae in a single pulse by mixing the bacteria with a single feed of live zooplankton prey in seawater. When examined $36 \mathrm{~h}$ after the addition of the bacteria, the light organs were found to harbour a small population of the symbiotic bacteria and by 8 days after addition of the bacteria, the size of the bacterial population had increased substantially (Fig. 4). The colonies arising from the light organs of these larvae were essentially uniform in size and shape and in the colour and intensity of light; in these characteristics, they appeared identical to colonies formed by the symbiotic bacteria from light organs of the adult $S$. versicolor, which have been identified as members of $P$. mandapamensis clade II and to luminous colonies from faeces released by the adult and juvenile $S$. versicolor (Kaeding et al., 2007; Dunlap et al., 2009; Dunlap \& Nakamura, 2011). To confirm the 

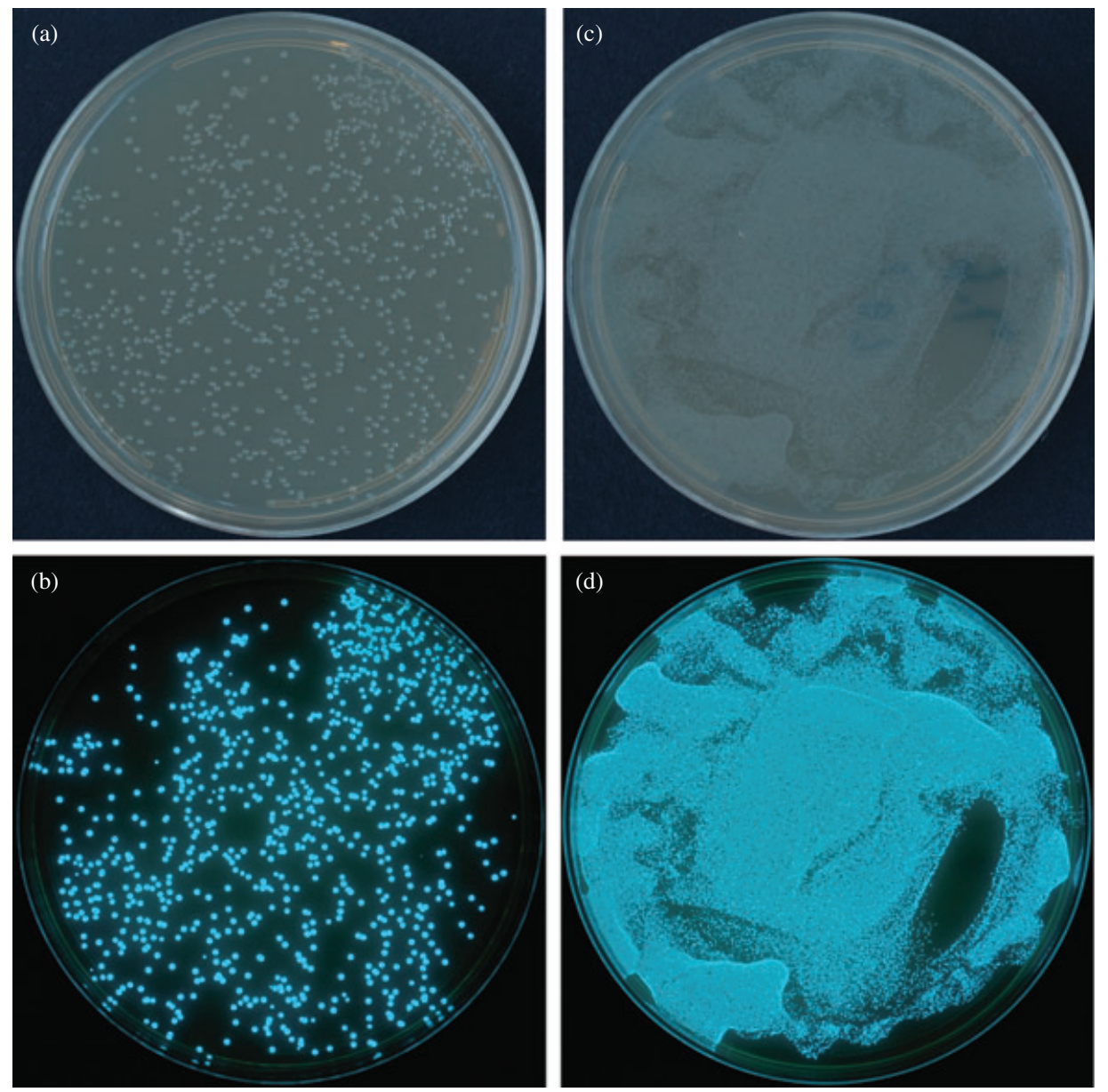

FIG. 4. Bacteria from light organs of experimentally colonized Siphamia versicolor larvae. (a) Photograph in the light of the single plate on which was spread the entire homogenate of the light organ of an 11.5 day post release (dpr) specimen $36 \mathrm{~h}$ after presentation of bacteria to the larva. (b) Same plate as in (a) photographed in the dark by the blue-green light produced by the colonies of symbiotic luminous bacteria. Approximately 820 colonies, all luminous, were present, indicating a small population of symbiotic bacteria in the light organ. (c) Photograph in the light of a plate on which was spread one half of the homogenate of the light organ of an $18 \mathrm{dpr}$ specimen 8 days after presentation of bacteria to the larva. (d) Same plate as in (c) photographed in the dark by the blue-green light produced by the colonies of symbiotic luminous bacteria. The colonies on this plate, due to their number and crowding, were too many to count, indicating a substantially larger population of symbiotic bacteria in the light organ after 8 days compared to $36 \mathrm{~h}$. Plates are standard $100 \mathrm{~mm}$ diameter, $15 \mathrm{~mm}$ deep, disposable plastic Petri dishes. Several colonies were picked from the plates and analysed by luxA sequence analysis; all were identified as Photobacterium mandapamensis clade II, members of the same clade of bacteria as isolated from light organs of adult S. versicolor (Kaeding et al., 2007).

identity of the bacteria recovered from light organs of the experimentally colonized larvae, luxA gene sequences of representative strains were analysed; all were confirmed by this criterion to be members of $P$. mandapamensis clade II. These results establish that the symbiosis can be experimentally initiated in aposymbiotic animals 
by presenting them with the symbiotic bacteria in association with zooplankton prey in seawater and that the light organs of the larvae are receptive to colonization at 10 dpr. Furthermore, these results establish that the symbiosis is initiated by bacteria acquired from the environment.

\section{DEVELOPMENTAL TIMING OF SYMBIOSIS INITIATION}

To determine if $S$. versicolor can initiate the symbiosis earlier in development than $10 \mathrm{dpr}$, the bacteria were presented to aposymbiotic larvae at $4 \mathrm{dpr}$ and daily thereafter. Light organs of these larvae, when sampled at $7 \mathrm{dpr}$, lacked bacteria detectable by microscopy (Fig. 5) and by microbiological cultivation. In contrast, light organs of the larvae sampled at $10 \mathrm{dpr}$ contained large numbers of the symbiotic bacteria visible by microscopy (Fig. 5) and by microbiological cultivation. These results demonstrate that $S$. versicolor can initiate the symbiosis, i.e. the light organ first becomes receptive to colonization, shortly after $7 \mathrm{dpr}$ development, at 8-10 dpr, but apparently not earlier than $7 \mathrm{dpr}$.

\section{ALTERED MORPHOLOGY OF COLONIZED LIGHT ORGANS}

Light organs in aposymbiotic larvae continued to grow in the absence of the bacteria, progressively increasing in volume (Figs 3 and 5). Uncolonized light organs, however, differed morphologically from light organs colonized by the symbiotic bacteria (Fig. 5). In uncolonized light organs, the tissue making up the core of the light organ exhibited an undifferentiated appearance; specifically, cells forming the light-organ chambers appeared swollen, and they filled much of the core of the light organ. In contrast, cells forming the light-organ chambers in light organs colonized by bacteria exhibited a differentiated appearance; they were thinner and delimited larger and more-well defined chamber lumina. These differences suggest that the presence of the symbiotic bacteria induces morphological changes in the cells composing the core tissue of the light organ.

\section{DISCUSSION}

Symbiont acquisition is an event critical to the survival of fishes that utilize symbiotic luminous bacteria for light production. Establishment of the symbiosis provides the members of each new generation of the fish with the ability to emit light, a metabolic capability necessary for juvenile and adult existence; the light is used, depending on the species, for sex-specific signalling, avoiding predators or attracting and illuminating prey (Urbanczyk et al., 2011a). When in the fish's development and how the bacteria are acquired, however, remain largely unknown for any of the more than 460 species of bacterially luminous fishes, which are found in 21 families of seven teleost orders (Herring \& Morin, 1978; Nelson, 2006; Froese \& Pauly, 2012). Here, through rearing of aposymbiotic larvae of $S$. versicolor and experimental initiation of the symbiosis, it is demonstrated that $S$. versicolor can survive and develop for an extended period under laboratory conditions in the absence of symbiotic bacteria, that substantial development of S. versicolor and of its light organ are necessary, regardless of the presence of the bacteria, before the symbiosis is 


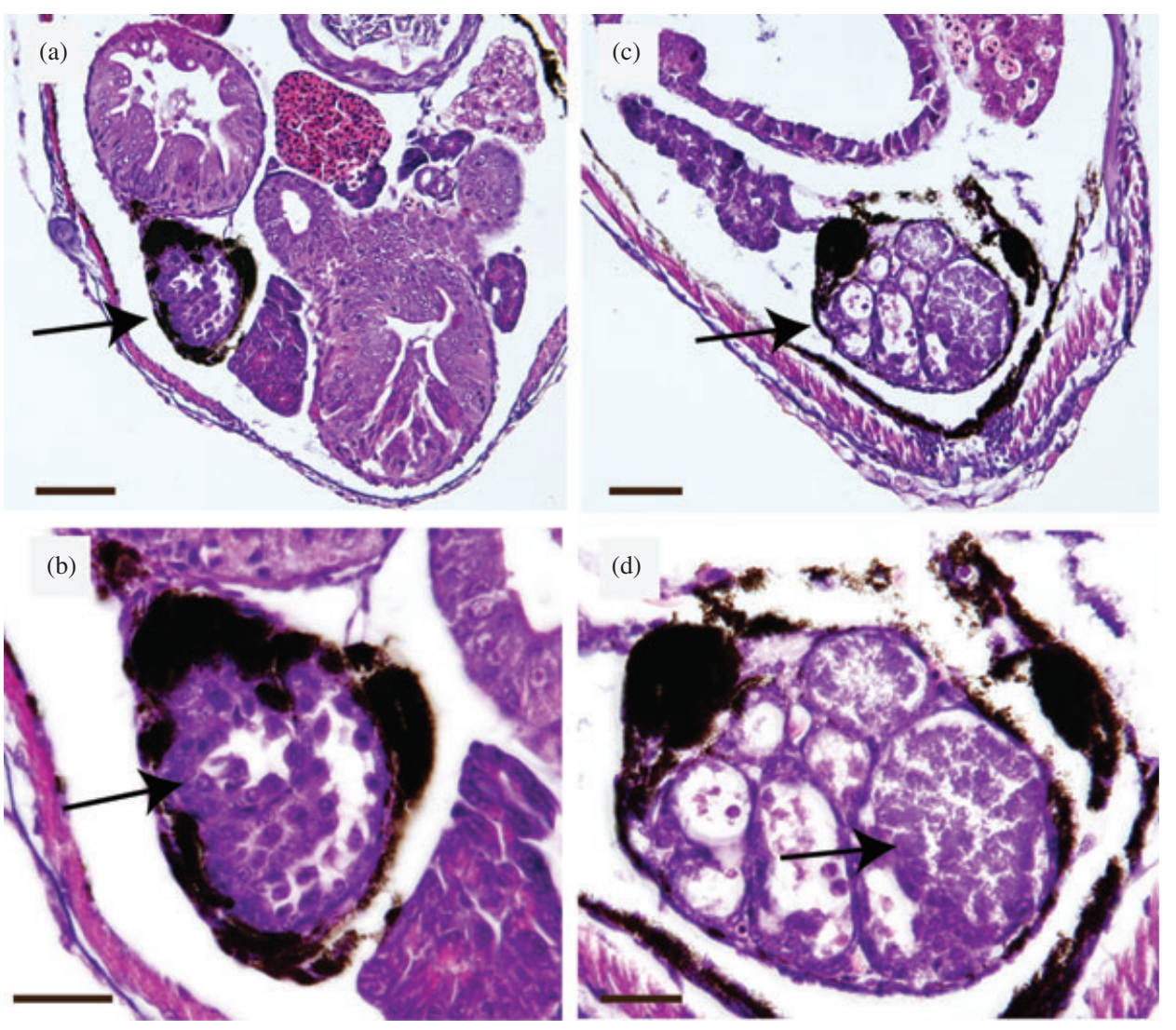

FIG. 5. Light organs of larvae of Siphamia versicolor cultured in the presence of symbiotic bacteria. (a) Light organ $(\longrightarrow)$ of a 7 day post-release (dpr) specimen that had been cultured in the presence of symbiotic bacteria for 3 days, i.e. from $4 \mathrm{dpr}$ (scale bar $=100 \mu \mathrm{m}$ ). (b) Enlargement of (a) showing the swollen undifferentiated cells $(\rightarrow$ ) forming the light-organ chambers and the absence of bacteria in the chamber lumina (scale bar $=60 \mu \mathrm{m}$ ). (c) Light organ $(\longrightarrow)$ of a $10 \mathrm{dpr}$ specimen that had been cultured in the presence of symbiotic bacteria for 6 days, i.e. from $4 \mathrm{dpr}$ (scale bar $=60 \mu \mathrm{m}$ ). (d) Enlargement of (c) showing the presence of masses of bacterial cells $(\rightarrow)$ within the light-organ chambers and the differentiated appearance of the cells forming the chambers (scale bar $=30 \mu \mathrm{m}$ ). Sections were $4 \mu \mathrm{m}$ thick and were stained with haematoxylin and eosin.

initiated and that the symbiotic bacteria are acquired from the environment and not by direct maternal or paternal transfer. The abilities to culture larvae of $S$. versicolor and to reconstitute its symbiosis with $P$. mandapamensis are important steps in establishing the experimental tractability of this model vertebrate and microbe mutualism.

Despite the phylogenetic diversity and abundance of bacterially luminous fishes and their ecological importance as predators and prey in marine habitats, little definitive work had been carried out on the developmental and microbiological events surrounding inception of their bioluminescent symbioses (Dunlap et al., 2007, 2008). Prior to the work reported here, Leis \& Bullock (1986) documented the morphology of wild-caught larvae of $S$. versicolor and characterized the development of the light 
organ and the stage at which bacteria first are seen to be present in the light organ. In $S$. versicolor, a paternal mouth brooder, the light organ begins to develop within 1 day after release of larvae from the mouth of the male $S$. versicolor, it arises from a proliferation and differentiation of intestinal epithelium and it remains free of bacteria through $7 \mathrm{dpr}$ development (Dunlap et al., 2009). For the leiognathid Nuchequula nuchalis (Temminck and Schlegel, 1845), which harbours Photobacterium leiognathi in an internal, pre-gastric light organ, Wada et al. (1999) demonstrated that the symbiotic bacteria could be acquired, presumably from seawater, by 45-60 day old aposymbiotic juveniles when the juveniles were maintained in the presence of the adult $N$. nuchalis, which release the bacteria into seawater. A microbiological analysis of early developmental stages of wild-caught $N$. nuchalis larvae revealed that the light organ begins to develop several days before the acquisition of symbiotic bacteria and that the symbiosis is initiated following a migration of larvae from offshore to the wave zone, where P. leiognathi is more abundant (Dunlap et al., 2008). The limited work done on bacterially luminous fishes contrasts with the very substantial body of knowledge that has been assembled over the past 20 years on the bioluminescent symbiosis of the sepiolid squid Euprymna scolopes and its luminous bacterial symbiont, Aliivibrio fischeri (previously classified as Vibrio fischeri) (Wei \& Young, 1989; McFall-Ngai \& Ruby, 1991; Nyholm \& McFall-Ngai, 2004; Ruby, 2006; Urbanczyk et al., 2007; Ast et al., 2009; McFall-Ngai et al., 2010).

A major limitation to deeper understanding of bioluminescent symbiosis in fishes is host life style; most bacterially luminous fishes are either open water, rapidly swimming species (e.g. leiognathids and acropomatids), or they are deep dwelling (e.g. macrourids and ceratioids). These attributes make their live capture and longterm survival in aquariums problematic. In contrast, the life style of $S$. versicolor differs from many other bacterially luminous fishes. As small-sized, shallow reefdwelling fish that are quiescent during the day in their association with an urchin, $S$. versicolor is relatively easy to collect alive. In captivity, S. versicolor readily feeds, survives well, reproduces and exhibits apparently normal luminescence behaviour; these attributes facilitate experimental analysis of $S$. versicolor and its symbiosis (Dunlap \& Nakamura, 2011). Nonetheless, captive rearing of larvae is a major constraint to progress in aquaculture (Wittenrich, 2007; Olivotto et al., 2011), especially for fishes with the small mouth gape and body size of newly released $S$. versicolor larvae. A further complication is the current lack of knowledge of the prey types and sizes consumed by $S$. versicolor larvae in the wild. Despite these challenges, S. versicolor was cultured here through much of its larval development, a major advance over previous work (Dunlap et al., 2009). The improved survival of larvae apparently was due to increases in the densities of zooplankton prey provided to the larvae and the use of algae and continuous illumination, which appeared to enhance the frequency of prey encounter. It should be noted also that, although settlement behaviour was not observed during this study, morphological attributes of 28 dpr larvae, including squamation and complete development of the caudal complex, suggest that the larvae were competent to settle. Settlement in other apogonids, depending on the species, ranges from 14 to 30 days, with an average planktonic larval duration of 20 days (Ishihari \& Tachihara, 2011). The habitat specificity of juvenile and adult $S$. versicolor suggests that a settlement cue might be required to complete metamorphosis and initiate settlement to the benthic substratum, i.e. the sea urchin. Larvae of some marine fishes are capable of delaying metamorphosis 
until such cues are received (McCormick, 1999). These considerations suggest that with some additional improvements in the mariculture system, it will be possible to bring $S$. versicolor through larval development to settlement and the juvenile stage. The ability to do so will facilitate a variety of studies on the developmental biology of $S$. versicolor and its symbiosis.

The ability established here to culture larvae of $S$. versicolor for extended periods in an aposymbiotic state allows the inception of symbiosis to be examined experimentally. In S. versicolor larvae, the light organ and a duct composed of multiple tubules arise from a proliferation and differentiation of the intestinal epithelium near the second bend of the developing intestine (Iwai, 1959, 1971; Tominaga, 1964; Leis \& Bullock, 1986; Dunlap et al., 2009; Dunlap \& Nakamura, 2011). The symbiotic bacteria presumably gain access to the light organ via nascent duct tubules that connect to the intestine; no other entry into the nascent light organ is evident. In this regard, the ability to reconstitute the symbiosis experimentally by presentation of the bacteria mixed with zooplankton in seawater to aposymbiotic larvae suggests that ingestion of the bacteria and their transit down the intestine, as the ingested zooplankton prey are digested, are necessary steps in the colonization of the light organ. Alternatively, it is possible that the symbiotic bacteria are ingested directly from seawater. Regardless, initiation of the symbiosis apparently requires $>7$ days of post-release larval development, even when the bacteria are available earlier in larval development. This delay in symbiosis initiation, until 8-10 dpr, suggests that establishment of the connection between the intestinal lumen and the light-organ duct requires further development beyond $7 \mathrm{dpr}$. Alternatively, it is possible that host-cell layers that form the connection remain unreceptive to interaction with the symbiotic bacteria until later or that response to that interaction, i.e. opening a connection between the intestinal lumen and the duct tubules, requires additional time. Nothing further is currently known about the process by which the bacteria gain access to the nascent light organ or about the possible specificity of the interactions leading to the colonization of the light organ. It seems likely that also in the wild, the larvae acquire the bacteria while feeding, but nothing is known at this time about prey taken by $S$. versicolor larvae in the wild or if the symbiotic bacteria are associated with those prey. These considerations differ markedly from initiation of bioluminescent symbiosis in E. scolopes by the luminous bacterium A. fischeri; E. scolopes undergoes direct development, hatching from eggs as aposymbiotic juveniles with well-formed light organs that are immediately receptive to bacterial colonization (Wei \& Young, 1989; McFall-Ngai \& Ruby, 1991). Ciliated epithelial appendages bring the bacteria from seawater pumped through the squid mantle cavity directly to pores that enter into crypts forming the bilobed light organ. Therefore, presentation of A. fischeri in seawater to the aposymbiotic hatchling E. scolopes allows rapid colonization of the light organ (McFall-Ngai \& Ruby, 1991). Ingestion and intestinal transit of the symbiotic bacteria are not involved in the formation of the symbiosis in E. scolopes. Regardless of how colonization of the light organ occurs in S. versicolor, the ability to experimentally initiate the symbiosis with $P$. mandapamensis will facilitate studies to examine the bacterial specificity of the association and to identify the bacterial genes necessary for initiation and maturation of the symbiosis.

The survival of aposymbiotic larvae of $S$. versicolor for extended periods suggests that the bacteria do not provide $S$. versicolor with a needed nutritional factor or a metabolic capability other than luminescence. These observations also indicate that 
the development and overall differentiation of the tissues of the luminescence system apparently are not conditional in the presence of bacteria. The nature of the symbiosis in $S$. versicolor at this level therefore appears to parallel that in E. scolopes, which survives, grows and develops normally, and the core components of the luminescence system, the light organ, reflector and lens, develop normally in the absence of the symbiotic bacteria, A. fischeri (Claes \& Dunlap, 2000). Furthermore, aposymbiotic E. scolopes retains the ability to initiate symbiosis into reproductive adulthood (Claes \& Dunlap, 2000). The data and observations on S. versicolor, however, are not yet sufficiently detailed to reveal small but possibly biologically important differences in the survival, development and reproduction of aposymbiotic and colonized host animals. It is possible therefore that additional detailed study of S. versicolor will identify such differences.

With respect to the luminescence system of $S$. versicolor, the light organ, reflector and duct, which begin to form within $1 \mathrm{dpr}$, and the diffuser, the formation of which is evident by $7 \mathrm{dpr}$, continue developing in the absence of the bacteria. Nonetheless, presence of the bacteria correlates with a more differentiated appearance of the cells forming the light-organ chambers, which suggests that the bacteria induce changes within the light organ at the cellular level, a possible parallel to changes in the light organ of E. scolopes upon colonization by A. fischeri (Montgomery \& McFall-Ngai, 1994; Doino \& McFall-Ngai, 1995; Foster et al., 2000).

Bioluminescent symbioses between fishes and luminous bacteria, because of their bacterial specificity, have the potential to reveal substantial insight into how vertebrate animals form stable alliances with individual kinds of symbiotic bacteria and thereby acquire a needed nutritional factor or metabolic capability. Because of their simplicity and stability, these associations also have potential as models for more microbiologically complex and variable vertebrate and microbe associations, such as those of the human gastrointestinal tract (Kau et al., 2011; Young, 2012). The progress reported here, on culturing larvae of $S$. versicolor and on reconstituting its symbiosis with $P$. mandapamensis, is a key step in establishing this association as an experimentally tractable model vertebrate and microbe mutualism.

The authors thank R. Nozu and S. Kadena for assistance in collecting and maintaining $S$. versicolor, J. Harrison, J. Poore and K. Pasyk for assistance with histology and K. Dougan for technical assistance. This study is a contribution from Sesoko Station, Tropical Biosphere Research Center, University of the Ryukyus, and was supported by a grant to P.V.D. from the University of Michigan Center for Japanese Studies and by an NSF EAPSI Award to A.L.G..

\section{References}

Arvedlund, M., McCormick, M. I. \& Ainsworth, T. (2000). Effects of photoperiod on growth of larvae and juveniles of the anemonefish Amphiprion melanopus. Naga (ICLARM Quarterly) 23, 18-23.

Ast, J. C. \& Dunlap, P. V. (2004). Phylogenetic analysis of the lux operon distinguishes two evolutionarily distinct clades of Photobacterium leiognathi. Archives of Microbiology 181, 352-361. doi: 10.1007/s00203-004-0663-7

Ast, J. C., Urbanczyk, H. \& Dunlap, P. V. (2009). Multi-gene analysis reveals previously unrecognized phylogenetic diversity in Aliivibrio. Systematic and Applied Microbiology 32, 379-386. doi: 10.1016/j.syapm.2009.04.005

Breder, C. M. Jr., \& Rosen, D. E. (1966). Modes of Reproduction in Fishes. Garden City, NY: Natural History Press. 
Claes, M. \& Dunlap, P. V. (2000). Aposymbiotic culture of the sepiolid squid Euprymna scolopes: role of the symbiotic bacterium Vibrio fischeri in host animal growth, development, and light organ morphogenesis. Journal of Experimental Zoology 286, 280-296. doi: 10.1002/(SICI)1097-010X

Doino, J. A. \& McFall-Ngai, M. J. (1995). A transient exposure to symbiosis-competent bacteria induces light organ morphogenesis in the host squid. Biological Bulletin 189, $347-355$.

Douglas, A. E. (1994). Symbiotic Interactions. Oxford: Oxford University Press.

Dunlap, P. V. \& Nakamura, M. (2011). Functional morphology of the luminescence system of Siphamia versicolor (Perciformes: Apogonidae), a bacterially luminous coral reef fish. Journal of Morphology 272, 897-909. doi: 10.1002/jmor.10956

Dunlap, P. V., Ast, J. C., Kimura, S., Fukui, A., Yoshino, T. \& Endo, H. (2007). Phylogenetic analysis of host-symbiont specificity and codivergence in bioluminescent symbioses. Cladistics 23, 507-523. doi: 10.1111/j.1096-0031.2007.00157.x

Dunlap, P. V., Davis, K. M., Tomiyama, S., Fujino, M. \& Fukui, A. (2008). Developmental and microbiological analysis of the inception of bioluminescent symbiosis in the marine fish Nuchequula nuchalis (Perciformes: Leiognathidae). Applied and Environmental Microbiology 74, 7471-7481. doi: 10.1128/AEM.01619-08

Dunlap, P. V., Kojima, Y., Nakamura, S. \& Nakamura, M. (2009). Inception of formation and early morphogenesis of the bacterial light organ of the sea urchin cardinalfish, Siphamia versicolor (Perciformes, Apogonidae). Marine Biology 156, 2011-2020. doi: $10.1007 / \mathrm{s} 00227-009-1232-\mathrm{z}$

Eibl-Eibesfeldt, I. (1961). Eine Symbiose zwischen Fischen (Siphamia versicolor) und Seeigeln. Zeitschrift für Tierpsychologie 18, 56-59.

Foster, J. S., Apicella, M. A. \& McFall-Ngai, M. J. (2000). Vibrio fischeri lipopolysaccharide induces developmental apoptosis, but not complete morphogenesis, of the Euprymna scolopes symbiotic light organ. Developmental Biology 226, 242-254. doi: 10.1006/ dbio.2000.9868

Haneda, Y. (1965). Observations on a luminous apogonid fish, Siphamia versicolor, and on others of the same genus. Science Reports of the Yokosuka City Museum 11, 1-12.

Herring, P. J. \& Morin, J. G. (1978). Bioluminescence in fishes. In Bioluminescence in Action (Herring, P. J., ed.), pp. 273-329. London: Academic Press.

Hobson, E. S. (1972). Activity of Hawaiian reef fishes during the evening and morning transitions between daylight and darkness. Fishery Bulletin 70, 715-740.

Hobson, E. S. (1991). Trophic interactions of fishes specialized to feed on zooplankters above coral reefs. In The Ecology of Fishes on Coral Reefs (Sale, P. F., ed.), pp. 69-95. San Diego, CA: Academic Press.

Ishihara, T. \& Tachihara, K. (2011). Pelagic larval duration and settlement size in Apogonidae, Labridae, Scaridae, and Tripterygiidae species in a coral lagoon of Okinawa Island, southern Japan. Pacific Science 65, 87-93. doi: 10.2984/65.1.087

Iwai, T. (1958). A study of the luminous organ of the apogonid fish Siphamia versicolor (Smith and Radcliffe). Journal of the Washington Academy Sciences 48, 267-270.

Iwai, T. (1959). Notes on the luminous organ of the apogonid fish, Siphamia majimai. American Museum of Natural History 13, 545-550.

Iwai, T. (1971). Structure of luminescent organ of apogonid fish, Siphamia versicolor. Japanese Journal of Ichthyology 18, 125-127.

Kaeding, A. J., Ast, J. C., Pearce, M. M., Urbanczyk, H., Kimura, S., Endo, H., Nakamura, M. \& Dunlap, P. V. (2007). Phylogenetic diversity and co-symbiosis in the bioluminescent symbioses of Photobacterium mandapamensis. Applied and Environmental Microbiology 73, 3173-3182. doi: 10.1128/AEM.02212-06

Kau, A. L., Ahern, P. P., Griffin, N. W., Goodman, A. L. \& Gordon, J. I. (2011). Human nutrition, the gut microbiome and the immune system. Nature 474, 327-326. doi: 10.1038 /nature 10213

Kimura, S., Tsumoto, K. \& Mori, K. (1984). Fauna of fishes gathering around a fish lamp in Ago Bay, Mie Prefecture. Bulletin of the Faculty of Fisheries, Mie University 11, 227-239.

Knowlton, N. \& Rohwer, F. (2003). Multispecies microbial mutualisms on coral reefs: the host as a habitat. American Naturalist 162, S51-S62. 
Lachner, E. A. (1955). Inquilinism and a new record for Paramia bipunctata, a cardinal fish from the Red Sea. Copeia 1955, 53-54.

Leis, J. M. \& Bullock, S. (1986). The luminous cardinalfish Siphamia (Pisces, Apogonidae), development of larvae and the luminous organ. In Indo-Pacific Fish Biology, Proceedings of the Second International Conference on Indo-Pacific Fish (Uyeno, T., Arai, R., Taniuchi, T. \& Matsuura, K., eds), pp. 703-714. Tokyo: Japan Ichthyological Society.

Masuda, H. \& Allen, G. R. (1993). Meeresfische der welt-groß-Indopazifische region. Herrenteich, Melle: Tetra Verlag.

McCormick, M. I. (1999). Delayed metamorphosis of a tropical reef fish (Acanthurus triostegus): a field experiment. Marine Ecology Progress Series 176, 25-38.

McFall-Ngai, M. J. \& Ruby, E. G. (1991). Symbiont recognition and subsequent morphogenesis as early events in an animal-bacterial mutualism. Science 254, 1491-1494.

McFall-Ngai, M. J., Nyholm, S. V. \& Castillo, M. G. (2010). The role of the immune system in the initiation and persistence of the Euprymna scolopes-Vibrio fischeri symbiosis. Seminars in Immunology 22, 48-53. doi: 10.1016/j.smim.2009.10.003

McFarland, W., Wahl, C., Suchanek, T. \& McAlary, F. (1999). The behavior of animals around twilight with emphasis on coral reef communities. In Adaptive Mechanisms in the Ecology of Vision (Archer, S. N., Djamgoz, M. B. A., Loew, E. R., Partridge, J. C., \& Vallerga, S., eds), pp. 583-628. Dordrecht: Kluwer Academic Publishers.

Montgomery, M. K. \& McFall-Ngai, M. J. (1994). Bacterial symbionts induce host organ morphogenesis during early development of the squid Euprymna scolopes. Development 120, 1719-1729.

Muller-Parker, G. \& D'Elia, C. F. (1997). Interactions between corals and their symbiotic algae. In Life and Death of Coral Reefs (Birkeland, C., ed.), pp. 96-113. New York, NY: Chapman \& Hall.

Nelson, J. S. (2006). Fishes of the World. Hoboken, NJ: John Wiley and Sons.

Nyholm, S. V. \& McFall-Ngai, M. J. (2004). The winnowing: establishing the squid-Vibrio symbiosis. Nature Reviews Microbiology 2, 632-642. doi: 10.1038/nrmicro957

Olivotto, I., Planas, M., Simões, N., Holt, G. J. \& Avella, M. A. (2011). Advances in breeding and rearing marine ornamentals. Journal of the World Aquaculture Society 42, 135-166. doi: 10.1111/j.1749-7345.2011.00453.x

Pasternak, Z., Bachar, A., Abelson, A. \& Achituv, Y. (2004). Initiation of symbiosis between the soft coral Heteroxenia fuscescens and its zooxanthellae. Marine Ecology Progress Series 279, 113-116.

Puvanendran, V. \& Brown, J. A. (2002). Foraging, growth and survival of Atlantic cod larvae reared in different light intensities and photoperiods. Aquaculture 214, 131-151.

Ruby, E. G. (2006). Lessons from a cooperative, bacterial-animal association: the Vibrio fischeri-Euprymna scolopes light organ symbiosis. Annual Review of Microbiology 50, 591-624.

Tamura, R. (1982). Experimental observations on the association between the cardinalfish (Siphamia versicolor) and the sea urchin (Diadema setosum). Galaxea 1, 1-10.

Tominaga, Y. (1964). Notes on the fishes of the genus Siphamia (Apogonidae), with a record of S. versicolor from the Ryukyu Islands. Japanese Journal of Ichthyology 12, 10-17.

Urbanczyk, H., Ast, J. C., Higgins, M. J., Carson, J. \& Dunlap, P. V. (2007). Reclassification of Vibrio fischeri, Vibrio logei, Vibrio salmonicida and Vibrio wodanis as Aliivibrio fischeri gen. nov., comb. nov., Aliivibrio logei comb. nov., Aliivibrio salmonicida comb. nov., and Aliivibrio wodanis comb. nov. International Journal of Systematic and Evolutionary Microbiology 57, 2823-2829. doi: 10.1099/ijs.0.65081-0

Urbanczyk, H., Ast, J. C. \& Dunlap, P. V. (2011a). Phylogeny, genomics, and symbiosis of Photobacterium. FEMS Microbiology Reviews 35, 324-342. doi: 10.1111/j.15746976.2010.00250.X

Urbanczyk, H., Ogura, Y., Hendry, T. A., Gould, A. L., Kiwaki, N., Atkinson, J. T., Hayashi, T. \& Dunlap, P. V. (2011b). Genome Sequence of Photobacterium mandapamensis svers.1.1., the bioluminescent symbiont of the cardinal fish Siphamia versicolor. Journal of Bacteriology 193, 3144-3145. doi: 10.1128/JB.00370-11

Wada, M., Azuma, N., Mizuno, N. \& Kurokura, H. (1999). Transfer of symbiotic luminous bacteria from parental Leiognathus nuchalis to their offspring. Marine Biology 135, $683-687$. 
Wada, M., Kamiya, A., Uchiyama, N., Yoshizawa, S., Kita-Tsukamoto, K., Ikejima, K., Yu, R., Imada, C., Karatani, H., Mizuno, N., Suzuki, Y., Nishida, M. \& Kogure, K. (2006). Lux A gene of light organ symbionts of the bioluminescent fish Acropoma japonicum (Acropomatidae) and Siphamia versicolor (Apogonidae) forms a lineage closely related to that of Photobacterium leiognathi ssp. mandapamensis. FEMS Microbiology Letters 260, 186-192. doi: 10.1111/j.1574-6968.2006.00322.x

Wei, S. L. \& Young, R. E. (1989). Development of symbiotic bacterial bioluminescence in a nearshore cephalopod, Euprymna scolopes. Marine Biology 103, 541-546.

Weis, V. M., Reynolds, W. S., de Boer, M. D. \& Krupp, D. A. (2001). Host-symbiont specificity during onset of symbiosis between the dinoflagellates Symbiodinium spp. and planula larvae of the scleractinian coral Fungia scutaria. Coral Reefs 20, 301-308. doi: $10.1007 / \mathrm{s} 003380100179$

Wittenrich, M. L. (2007). The Complete Illustrated Breeder's Guide to Marine Aquarium Fishes. Neptune City, NJ: TFH Publications.

Yoshiba, S. \& Haneda, Y. (1967). Bacteriological study on the symbiotic luminous bacteria cultivated from the luminous organ of the apogonid fish, Siphamia versicolor and the Australian pine cone fish, Cleidopus gloriamaris. Science Reports of the Yokosuka City Museum 13, 82-84.

Young, V. B. (2012). The intestinal microbiota in health and disease. Current Opinion in Gasteroenterology 28, 63-69. doi: 10.1097/MOG.0b013e32834d61e9

\section{Electronic Reference}

Froese, R. \& Pauly, D. (2012). FishBase. Available at www.fishbase.org (accessed 24 March 2012). 